\title{
Our Journal is Moving Forward
}

Happy New Year to all enthusiastic authors and editorial team members. The Trends in Renewable Energy (TRE) successfully concluded the second volume, and heading to another year. We deeply appreciate your support, and are looking forward to continuously working with all colleagues around the world.

The 2016 TRE Author of the Year Award goes to Dr. Athanasios G. Lazaropoulos at the National Technical University of Athens, Greece. Dr. Lazaropoulos contributed over 10 high quality papers to our journal during last two years. The great support of the authors encourages us to improve.

The 2016 TRE Paper of the Year goes to "A Review of Hydrothermal Carbonization of Carbohydrates for Carbon Spheres Preparation" (DOI: 10.17737/tre.2015.1.1.009). Within a short period of time, this paper received 6 citations including 3 external citations. Both the effort of authors and the power of open-access showed impacts to the renewable energy field.

During last two years, we have been accumulating knowledge of running a scientific journal. Now is the time to move forward. We are pursuing to be indexed in renowned indexes, such as the Directory of Open Access Journals (DOAJ), the Science Citation Index (SCI of Web of Science Core Collection), and Ei Compendex.

To prepare this journal to pass the evaluations conducted by multiple indexes, the journal is now an open accessed, peer-reviewed semi-annual journal with completely Free-of-Charge publication policy (i.e. no cost to authors and readers). We will continue the TRE's mission to publish quality reviews, original research, and application-oriented papers, providing a communication platform that is run exclusively by scientists working in the renewable energy field. Papers are invited on any individual topic related to renewable energy or those that are interdisciplinary.

Bo Zhang

Editor in Chief

January 1, 2017

\section{cc) (1)}

This work is licensed under a Creative Commons Attribution 4.0 International License. 